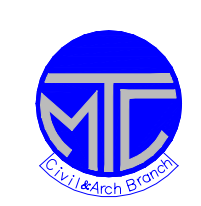

\title{
Activating the role of the trees in open spaces Analytical study on one of the armed forces homes
}

\author{
Hany mahmoud mohammed* \\ Mahmoud atiea tailab** \\ Adel yassen moharam***
}

\section{ABSTRACT}

Egyptians cities are experiencing a destructive unbalance in their urban environment as a consequence of the urbanization on green areas inside and outside the city limits . this results in gas, acoustical and lighting pollution affecting human taste and behavior leading to a Catastrophic cultural pollution .

Man caliph god on earth, he has an effective role, positive or negative in the balance of the urban environment with it's all phases, and we cane form that in a simple equation : ( a normal person work to find a natural and balanced environment or a natural and balanced environment create a normal person ). and any shortage in any part of this equation, cause a disequilibrium and balance leading to un normal pollution interaction with the environment .

Vegetation, when adequately provided, helps providing human psychological and behavioral balance in addition to the vital environmental balance. The goal of this research is to analyze the use of vegetation as an important landscape element in Egyptian urban spaces . in which this study doesn't take the enough attention as an element of the design and planning elements and not as complementary element to any of them, specially in the Egyptian city which become in a bad need to found an urban spaces contain the hard and soft landscape elements specially the plant element .

\footnotetext{
* Egyptian armed forces

** Dr. permanent staff in Dept. of Architecture Eng ,helwan university - Cairo, EGYPT

*** pro .Dr. in Dept. of Architecture Eng. Ian shams university - Cairo, EGYPT
} 


\section{INTRODUCTION.}

In the paste landscaping the green areas was taken from the view of welfare and luxury of the rich class or a kind of a mark to the building and extra ornament decorative element but now our contemporary environment faces many problems - specially in land use strategy field and protection of environment and planning as all and landscaping green areas takes a new concepts ( meaning ) one of them :-

It's kind of achievement the environment balance between the building and the outdoor, crowd and rarity, the vertical extension to the building and the horizontal extension to the space and between the balance of life inside a limited concrete block ( indoor ) an a free life released in the expanded spare to infinity ( outdoor ) .

This paper study a layout ( site ) of one of the armed forces homes and studying the urban design element of the space and the green areas and how to use it in better way to activate the role of trees in the site by :

Redistribution and redesigning it's place

Changing the existing kind and adding a new kind of trees to have a general recommendation to improve the quality of this special kind of the urban spaces ( armed forces homes ).

\section{KEY WORDS}

Urban design - Urban spaces - Landscaping - Environment balance

\section{The problem :}

The distribution of green area become a discretionary way and not by a scientific study acquainted with each element of the landscape elements, specially the trees because it has a characteristics in three dimension and planning and town escaping which become to many 
designers and engineers an absence knowledge, In addition to the human share from the green space, here we trying to increase it relative to the analytical study, that could be, by increasing the efficiency of it's property and it's role in the site in order to activate it, so the human could have a better share from its properties even it was an environmental, an architectural or planning characteristics .

\section{The Goal :}

The aim goal is to rise the role of tees in the site and increasing the green areas by given a suitable solutions to the site of the armed forces home - in the future we can use this solutions ( criteria ) in the other armed forces homes .

\section{How to activate the role of trees in the site ??}

The answer will be in two terms .

(A) Characterization of the landscape site

(B) Trees selection

Before selecting plants to use , the site should be accurately analyzed and characterized, and preparations should be made .

\section{(A) Characterization of the landscape site -}

a site analysis for bedding plants should include

1- Temperature averages for the color season

2- Amount of sunlight received daily

3- Rainfall overages and intervals between rain

4- Soil characteristics ( Drainage - Moisture - Retention ).

\section{(B) Important factors in tree selection}

1- Local soil \& water characteristics should be thoroughly investigated before 
selecting which trees to plant

2- Microclimatic influences

3- The size of trees relative to the space available

4- The rates of growth of the proposed trees

5- The general appearance and character

6- The effect of seasonal changes

7- length of life seasonal changes

8- cultural requirements ( Including pruning, fertilizing and protection from injects and diseases.

- That will be an delegation to us, to study the kind of trees well and its properties, and the importance and the effect of each kind in the landscape.

\section{The analytical study:}

o Infantry home one of the armed forces homes, the analytical study will deal with its site, and the soft landscape (plant - green).

o First we evaluate the existing situation and then we but some solution and recommendations to the problems.

ANALYTICAL STUDY
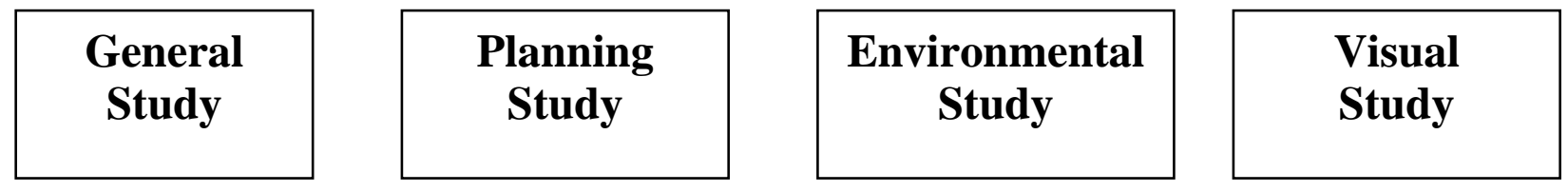

*General description To the site:

- Limits.

- Gates.

- Topography \& soil

- Land use.

- Axis. (pedestrian, roads).

- Focal points.
- Wind.

- Heat.

- Air pollution.

- Acoustical pollution.

- Lighting pollution.
- Style of building.

- Attracting points.

- Plant design.

- Soft \& hard landscape.

- Architectural style to the building.

- Irrigation method.

- Visitors categories.

- Reasons for visiting. 
* the studies that mention above ,is the studies in which the landscape designer must take it , to analyze the site, in this paper, we will deal with a specific studies and not all the studies

\section{Planning studies:}

(Land use - axis -focal points of gathering - visual studies)

- Land use:

Green areas $\rightarrow 21 \%$

Building $\rightarrow 16 \%$ ( market, bowling, hotel, multi purpose hall)

Pools $\rightarrow 0.7 \%$.

\section{- Focal point:}

There are a different kinds of focal point for gathering around the pools, at the gardens, recreation areas beside the mall.

\section{- Axis(pedestrian and roads):}

the open space of the home defined an a group of axis and pedestrian for people and cars $\rightarrow$ 25\% . * *infantry home layout (land use):

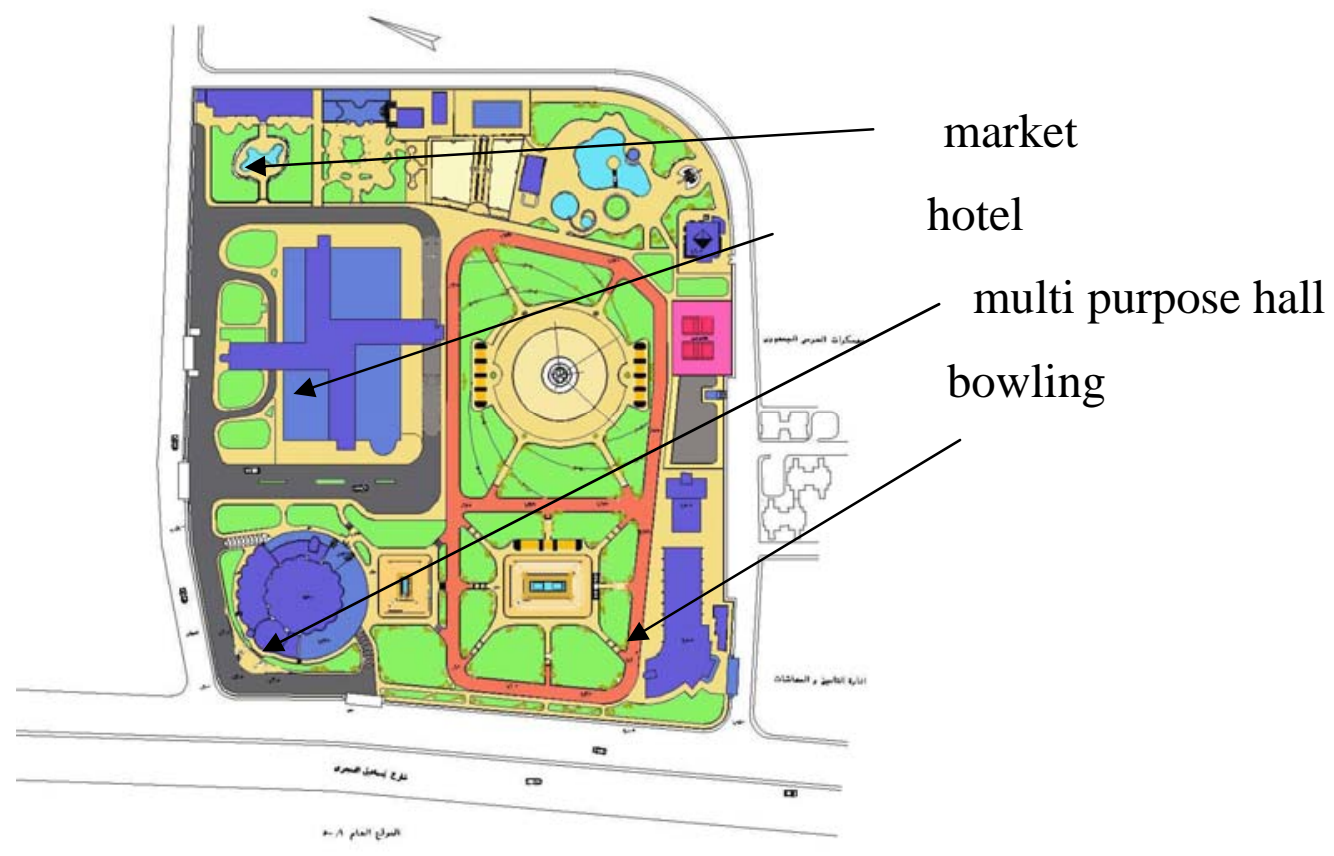




\section{Visual studies:}

(analyze the Architectural style of the building and the favored marks in from another point (side)

The building in the home site or layout has a different style.

But the modern style is the dominant style.

And due to the small area of the home site relatively, so most of the building are apparent visually for the visitors, and the plants setup doesn't have an order, and there is no confirmation to the axis by vegetation (trees).

\section{2- Natural element:}

- Green areas:

The open space in the infantry home site, contain a different kinds of trees shrubs, ground cover , and no palm trees, the area of the green space around $\left(14000 \mathrm{~m}^{2}\right)$ $21 \%$ for the open space.

- Kind of trees:

- Ficus nitida , deonix regia=poinciana ,washintonia filifrrra ,acacia nilotica.. . 


\section{Environmental study:}

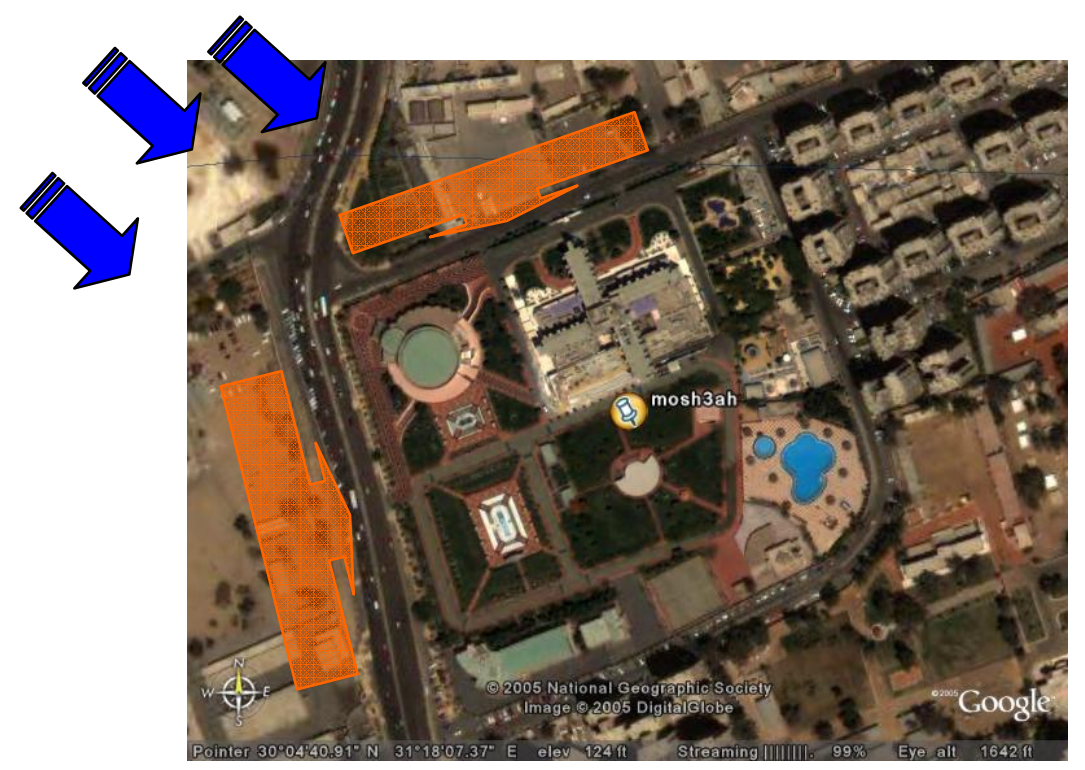

*Infantry home site (environmental study)

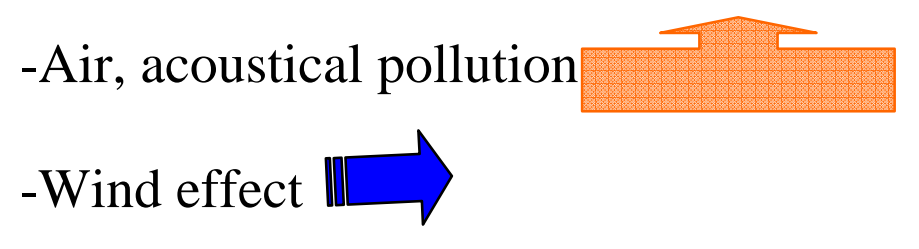

- an air \& acoustical pollution resulted from the surrounding streets from cars infect the infantry home site .

- visual pollution resulting from the surrounding building which has a poor architectural style ,and the trees designed in the landscape with no order. 


\section{Advantages:}

- different kinds of trees in the site .

- the focal points are seen to the visitors behind the hotel building .

- their are a Varity in the patterns materials .

- site structure designed in good way.

\section{Disadvantage:}

- $\quad$ shortage in trees design in the landscape .

- $\quad$ no protection from sun in the focal points by trees or by sunshade.

- The different kind of trees ,could be a nice view in the first look, but in dealing with its properties, the designer doesn't make the full use of it .

- The human share from green areas is less than normal (relative to the number of visitors and the resident in the hotel building) .

\section{Solving the Problem with plants :}

- we must take care of tree selection and its place to be plant, from the previous data we found that :

1. an evergreen trees should be located around the site to decrease the pollution (air, acoustical) and wind speed, like (araucaria excelsa , jacranda actifolia ,tipuana tipu ,ficus nitida ).

2. at the focal points ,must be shaded by deciduous trees to have use from it in summer by shading the open areas and in winter by the sun light passing through its branch canopy, like( melia azedarach, morus nigra , salix safsaf , salix babylonica ) .

3. to increase the human share from the green areas we can plant the roof of some building, like the bowling building and the hotel building, and there is some areas which need to be planted like the open space around the pools . 


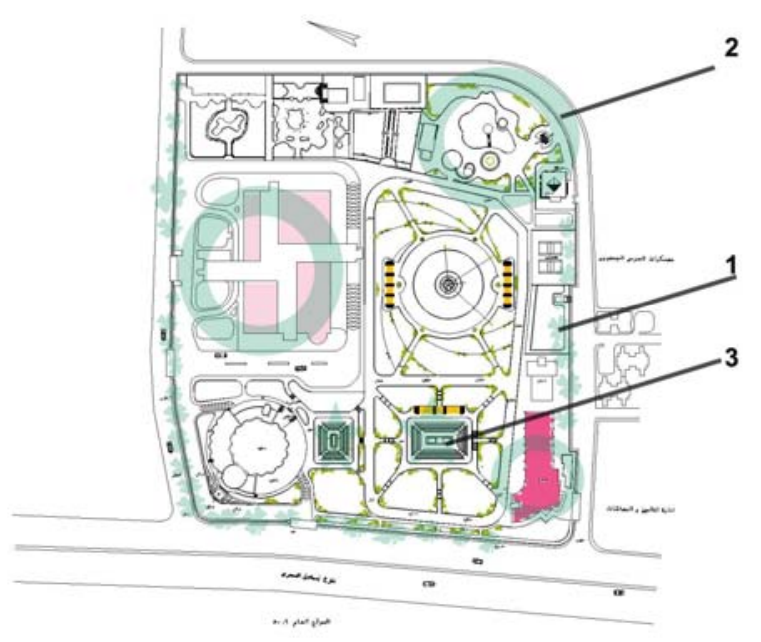

* infantry home site(solutions using trees)

4. we can use the palm trees to confirm the paths and the axis

\section{CONCLUSIONS}

1. tree should be seen as an integral part of the total three -dimensional urban structure , giving definition and meaning to the spaces between buildings and enhancing the building themselves .

2. Before selecting plants to use , the site should be accurately analyzed and characterized, and preparations should be made .

3. selecting the most appropriate species and variety of tree for a particular location and function profoundly influences the quality of a design .

4. their must be a qualified architectural engineering in urban landscape design having a good knowledge in trees kinds \& its behavior in urban spaces .

5. the best location ,arrangement and spacing for trees must be determined individually to meet the demands of different sites . 
6. we should establish some iconoclastic rules for tree planting, considering first how the trees are arranged and later , by examples, how the aggregation of trees are used to form the spaces in the city .the first illustration will deal with the small interstitial urban spaces, then we will return to central park to test the hypotheses .

\section{REFERENCE}

[1] Henry f.Arnold,” Trees in Urban Design ," (1980).

[2] Cathlen L. wolf,” Trees investment prings cities many happy Returns”, published paper .

[3] John cillman Lyle. “design for human ecosystem ', (1990).

[4] Brian clouscan., 'landscape design with plant', ( 1981).

[5] Christopher g.starbuck, 'selecting landscape plant, flowering trees', published paper.

[6] Mohammed hammad, 'garden trees and cities streets in the arabic world ', 1985. 